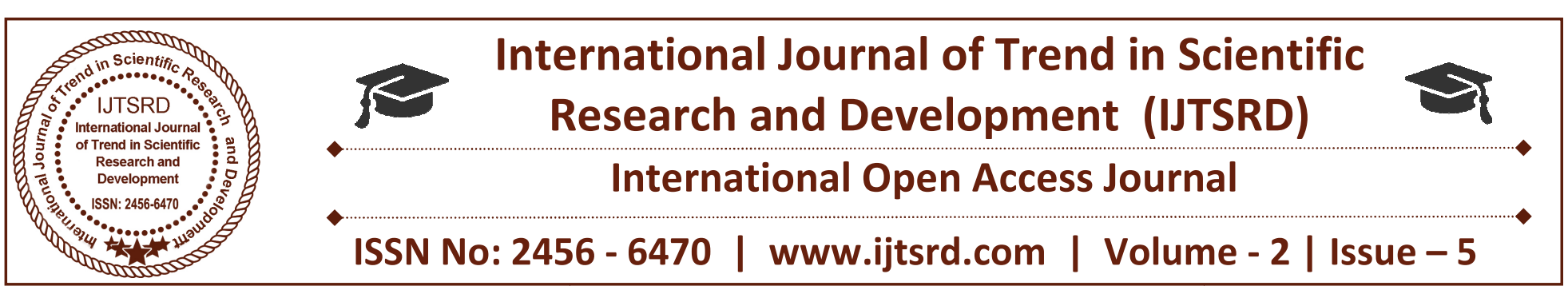

\title{
Water Conservation and Awareness - A Study in Kolkata
}

\author{
Sushovan Koner
}

Assistant Professor, ABS Academy of Science, Technology \& Management, Durgapur, West Bengal, India

\begin{abstract}
The Awareness is define as the state of level of consciousness where data can be confirmed by an observer. It is counselors of stimulation arising from within an from outside the reason when the term action is defined as the operating part that transits power to a mechanism. It is the secret of events that from a plot. As a result of which, West Bengal Board of Higher Secondary Education have included this subject as a compulsory subject in the School curriculum, where conversation of water is an important lesson. Theoretical knowledge helps to spread the awareness for conserving water among the students, but the practical application of knowledge is an important factor as well. Therefore along with the awareness \& actions, the study also helped to gather various suggestions of the students towards water conservation in Kolkata .Due to such disparity towards water conservation, therefore recommendations must be made to promote sustainable urban development in West Bengal, the Department of Environment Government of West Bengal commissioned the Calcutta Environment Management Strategy Action Plan (CEMSAP).
\end{abstract}

Keywords: Conservation, Awareness, suggestions

\section{INTRODUCTION}

There is an ever increasing awareness that water reserves, which are mobile, renewable natural resources exists in limited quantities. Moreover the available supply can very considerable during the course of a year.

As well as from year to year and from region to region, thus a conditions and indefinite expansion of water use is not possible. A situation of stability in the use of the water that is currently available must be sought. This should be one of the main strategic goals of a long term water management policy, there is an urgent need to find ways of saving reusing and retelling water. Controlling the excessive consumption of water and to develop methodology to improve water reserved management. Water conservation may have different measuring for different people. It may remind us of the publicity of collecting rain water in small tanks for domestic use an construction dams and reservoirs of recharging ground water whenever possible in order to save better water conservation habits. Stropping water full and uses, decreasing peak consumption and charging for water of the aggregated rates. It also means taking advantage of technological developments and improved management techniques; coordinating water resources planning and management with land use planning and economic and social planning and establishing nearer updated standards and regulations. If start water conservation means optimal water use. Its main purpose is different the efficient use of a limited resources which of essential to life.

\section{NEED OF THE STUDY}

The problem of water conservation in Kolkata with undoubtedly become increasing important. There is growing need to improve water resource management in general as well as the management of certain subsystems particularly those relating to water supply and sanitation. In 1985 an estimate f water availability and water demand of the year 2000-2020 was made and the respective balance was drawn up, the results showed that at the national level, the situation may be considered satisfactory, providing certain water quality problems can be adequately resolved. There are however problems at the regional level owing to the uneven distribution of available water resources in different areas and at different time of the year times of the year. Although in recent years the development of public water supply and sanitation services may be regarded as positive, there service are still a long way 
from being acceptable with marked differences in quality across the country in 1987, an average of $62.5 \%$ (varying between $90 \%$ and $24 \%$ in the various administrative districts of the population in Kolkata was served by a water supply system. In that same year, the percentage of the population with access to public sewerage systems was $42.3 \%$ (varying between $80 \%$ and $13 \%$ in the various districts) and wastewater treatment plants served only $11 \%$ of the population (varying between $41 \%$ and $4 \%$ in the various districts). Consequently, the need to make efficient use of existing water resources and optimine the investments required means that special attention should be paid to the topic of water conservation, which should be therefore the study was conducted to find out the awareness and actions of the students of Class-XI towards conservation of water in Kolkata.

\section{OBJECTIVE OF THE STUDY}

Inclusion of Environmental Education at the school level education has been made compulsory by the honorable Supreme Court of India. As a result of which, West Bengal Board of Higher Secondary Education have included this subject as a compulsory subject in the School curriculum, where conversation of water is an important lesson. Theoretical knowledge helps to spread the awareness for conserving water among the students, but the practical application of knowledge is an important factor as well.

Therefore the present study was conducted to find out the actual scenario of students awareness and their related action towards conserving the quality of water among the students of Class-XI in Kolkata on the basis of three schools selected from three different zones of Kolkata (North Kolkata, Central Kolkata \& South Kolkata).

\section{THE MAIN OBJECTIVES ARE:}

$>$ To find out the awareness of the students of Class-XI of three different schools of three zones of Kolkata towards water as an important resource \& conservation of the quality of the Water.

$>$ To identify the related actions of the students of Class-XI of three schools' towards conserving water and controlling the consumption of water in Kolkata.

$>$ To suggest ways for preventing water pollution reducing the loss or waste of water and for improving the efficient use of water.

\section{METHODOLOGY}

One set of questionnaire, distributed among the students of three different schools in Kolkata. Data procured from the questionnaire were processed \& represented by Multiple Bar Graphs.

\section{DELIMITATION OF THE STUDY:}

Study was mainly conducted in an urban area of a Metropolitan City (Kolkata), from where three English medium co-education schools, were selected.

One from North Kolkata (Airport English Medium School). One from Central Kolkata (St. Anthonys' High School) \& one from South Kolkata (South Point High School) of WBBHSE (West Bengal Board of Higher Secondary Education).

\section{SAMPLE:}

Study was conducted on a sample of 75 students of 3 schools of Class -XI under West Bengal Board of Higher Secondary Education. Out of 75 students, 25 students have been randomly selected from each school situated in three different zones (North, Central \& South) of Kolkata.

\section{TOOLS:}

Tools required for the study were one set of questionnaire-one for each students of Class-XI of three selected schools of Kolkata.

\section{RESULTS \& DISCUSSIONS}

With a view to find out students awareness \& related action towards conservation of water among the students of class-XI, the present study was conducted by giving one set of questionnaire to the students of three school under West Bengal Board of Higher Secondary Education (WBBHSE).

The main purpose of this survey is to find out awareness \& action of the students towards conservation of water in Kolkata.

All the schools chosen for this purpose are coeducational schools under WBBHSE.

The social background of the students studying in these schools are more or less homogeneous.

An attempt has been made here to analyse the responses of the students from the information (data) procured through the survey.

All the questions given in the questionnaire are 
International Journal of Trend in Scientific Research and Development (IJTSRD) ISSN: 2456-6470 positive in nature. Therefore in order to analyze the procured responses marked by students against each question, a suitable scale has been framed to analyze students actual.

Awareness (Section-I) \& Action (Section II) towards water conservation separately, which is:

$>$ scale for analyzing Awareness (SECTION-I) in $\%$

"Always" - High Awareness

"Frequently" \& "Rarely" - Moderate Awareness

"Occasionally" \& "Never"- Low Awareness

$>$ scale for analyzing Action taken by Awarded students (SECTION-II) in \%

"Always" - 'Taking High Actions'

"Frequently" \& "Rarely"- 'Taking Moderate Actions'

"Occasionally" \& "Never"- 'Taking Low Actions'

The analysis of the procured responses collected from 75 students (25 students taken from each school) revealed the following results for three different schools in Kolkata in three different zones:

\section{NORTH KOLKATA}

\begin{tabular}{|c|c|}
\hline $\begin{array}{l}\% \text { of total } \\
\text { A warded students }\end{array}$ & $\begin{array}{c}\% \text { of Action Taken by those } \\
\text { Awarded students }\end{array}$ \\
\hline $\begin{array}{c}60 \% \text { (High } \\
\text { Awareness) }\end{array}$ & 80\% (Taking High Actions) \\
\hline $\begin{array}{l}30 \% \text { (Moderate } \\
\text { Awareness) }\end{array}$ & $\begin{array}{l}60 \% \text { (Taking Moderate } \\
\text { Actions) }\end{array}$ \\
\hline $\begin{array}{l}10 \% \text { (Low } \\
\text { Awareness) }\end{array}$ & $50 \%$ (Taking Low Action) \\
\hline
\end{tabular}

CENTRAL KOLKATA

\begin{tabular}{|c|c|}
\hline $\begin{array}{c}\% \text { of total } \\
\text { A warded students }\end{array}$ & $\begin{array}{c}\% \text { of Action Taken by those } \\
\text { Awarded students }\end{array}$ \\
\hline $\begin{array}{l}50 \% \text { (High } \\
\text { Awareness) }\end{array}$ & $60 \%$ (Taking High Actions) \\
\hline $\begin{array}{l}\text { 30\% (Moderate } \\
\text { Awareness) }\end{array}$ & $\begin{array}{l}\text { 30\% (Taking Moderate } \\
\text { Actions) }\end{array}$ \\
\hline $\begin{array}{l}20 \% \text { (Low } \\
\text { Awareness) }\end{array}$ & $50 \%$ (Taking Low Action) \\
\hline
\end{tabular}

\section{SOUTH KOLKATA}

\begin{tabular}{|c|c|}
\hline $\begin{array}{c}\% \text { of total } \\
\text { Awarded students }\end{array}$ & $\begin{array}{c}\% \text { of Action Taken by those } \\
\text { Awarded students }\end{array}$ \\
\hline $\begin{array}{c}70 \% \text { (High } \\
\text { Awareness) }\end{array}$ & $80 \%$ (Taking High Actions) \\
\hline $\begin{array}{c}20 \% \text { (Moderate } \\
\text { Awareness) }\end{array}$ & $60 \%$ (Taking Moderate \\
\hline $\begin{array}{c}\text { Actions) } \\
\text { Awareness) }\end{array}$ & $60 \%$ (Taking Low Action) \\
\hline
\end{tabular}

Therefore in case of the total Awareness in three zones 45 students (60\%) showed High Awareness; 20 students $(26.66 \%)$ showed Moderate Awareness \& the rest 10 students (13.33\%) showed Low Awareness.

Again, the results of various Action towards water conservation by the Awarded students towards water conservation revealed, that about 32 students (73.33\%) were 'Taking High Actions' ; 10 students (26.6\%) were 'Taking Moderate Actions' ; \& about 5 students (53.33\%) were 'Taking Low Actions'.

The comparison of the total \% of 'Awareness' of three

Table No. 1 Sharing level of Awareness in there Zones of Kolkata

\begin{tabular}{|c|c|c|c|c|c|c|}
\hline \multirow{2}{*}{$\begin{array}{c}\text { Level of } \\
\text { A wareness }\end{array}$} & \multicolumn{2}{|c|}{\begin{tabular}{c} 
North Kolkata \\
\cline { 2 - 7 } \\
\cline { 2 - 7 } \\
Students
\end{tabular}} & \multicolumn{2}{c|}{ Central Kolkata } & \multicolumn{2}{c|}{ South Kolkata } \\
\hline High & 15 & $60 \%$ & 13 & $50 \%$ & 17 & $70 \%$ \\
\hline Mode & 8 & $30 \%$ & 7 & $30 \%$ & 5 & $20 \%$ \\
\hline Low & 2 & $10 \%$ & 5 & $20 \%$ & 3 & $10 \%$ \\
\hline
\end{tabular}
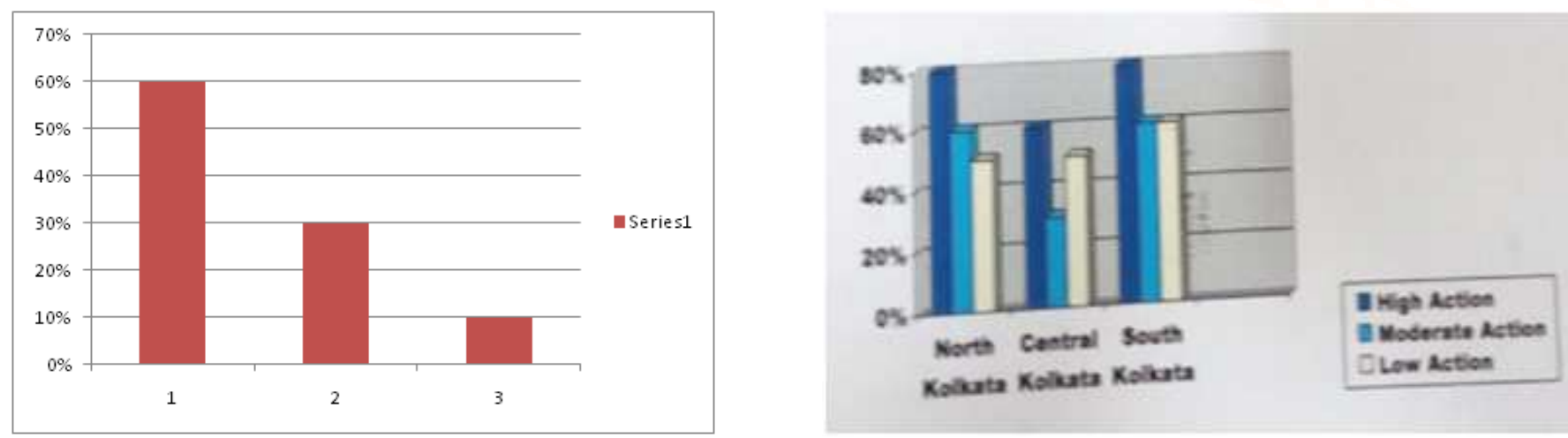


\section{Outdoor Suggestions}

$>$ One must water the lawn only when needed, generally once every three days during the summer. One must Check sprinkler timers and reduce watering times if necessary.

$>$ Adjusting watering schedule for each season. In fall, unless it's very hot outside, one can reduce watering time by half.

$>$ By December, one can turn off the irrigation system completely.

$>$ Checking sprinkler heads, valves and drip emitters once a month is necessary.

$>$ Water in the early morning is good for use. Many irrigation experts feel the best time to water is between midnight and 6 a.m. because evaporation is kept to a minimum.

$>$ One must apply a layer of organic mulch around plants to reduce moisture loss and kept weeds down.

$>$ One should ask the local nursery for the types of plants that will save you water. Water wise plants can be beautiful as well as practical.

$>$ One can use a broom to sweep off pavement rather than washing down sidewalks, drivewayys, as it wastes a lot of water and money.

\section{LIMITATIONS OF THE STUDY}

The study was conducted on the students of the three schools of West Bengal Board of Higher Secondary Education, selected from three different zones (North, Central \& South) of Kolkata whose exposure to modern world is limited.

Moreover the study concentrated on the co-education schools only.

Therefore, the opinion of the students studying in boys' \& girls' schools are not included.

Again, the students of the selected schools mainly coming from middle to higher middle class family, so as a result of which the other sections of the society are not represented in the study.

\section{CONCLUSION}

Therefore it can be concluded by saying that among the three schools, the school in South Kolkata showed the highest awareness \& taking high action towards conservation of water than other zones of Kolkata.

Such results showed that level of awareness \& action should be increased in North Kolkata \& Central
Kolkata in the order to eliminate the problems related to water conservation.

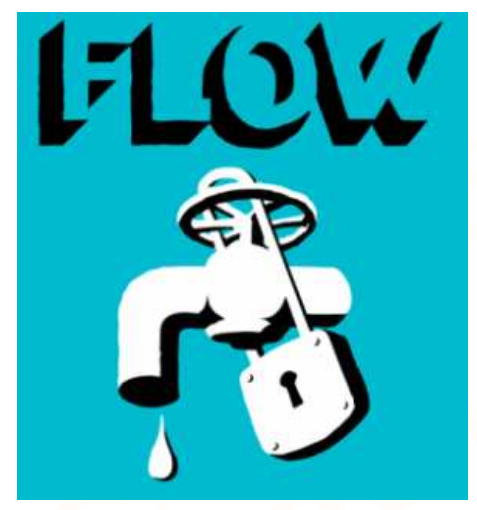

Due to such disparity towards water conservation, therefore recommendations must be made to promote sustainable urban development in West Bengal, the Department of Environment Government of West Bengal commissioned the Calcutta Environment Management Strategy Action Plan (CEMSAP). CEMSAP must aimed at supporting institutional strengthening and co-ordination across all sectors relevant to water conservation.

CEMSAP must try to identify the thrust sectors and corresponding environmental impacts.

CEMSAP must put stress on specific series of "Action Plans" in the following areas:

A. Haora Community Environment Management Plan

B. Local Environment Planning \& Management Capacity Building

C. Water Cess Improvement for WBPCB

D. Management of Wetlands and Canal Systems

Which South Kolkata reaches the highest level (1st). Following North Kolkata 2nd \& Central as 3rd. This is became the South Kolkata is more modern than Central and North, in terms of availability of latest development of city life than the other two zones of Kolkata.

Lastly, one open question was given to the students where they were asked to suggest various ways for concern action of water in Kolkata. Therefore along with the awareness \& actions, the study also helped to gather various suggestions of the students towards water conservation in Kolkata.

Suggestions given by students for Water conservation are as follows: 
General Suggestions

$>$ Fixing up the leaks is necessary as Leaks allow water and your money to go down the drain.

$>$ To help in detecting hidden leaks, one must turn off anything that uses water and see if the

$>$ Water meter is still moving. If it is, there could be a leak somewhere.

\section{Indoor suggestions}

$>$ Install water-efficient devices such as highefficiency toilet, high-efficiency clothes washing machines, low-flow shower heads and excess aerators.

$>$ One should run washing machine or dish washer with full load.

$>$ One must turn off faucet while brushing your teeth and shaving.

\section{BIBLIOGRAPHY \& REFERENCES}

1. Agarwal, Anil, Sunita Narain and Indira Khurana (eds). Making water everybody's Business: Practice and policy of Water Harvesting (New Delhi: Centre for Science and environment (2001).

2. Agarwal, Anil and Sunita Narain (eds). Drying Wisdom: Rise, Fall and Potential of India's Traditional Water Harvesting Systems (New Delhi: Centre for Science and Environment. (1997).

3. Agarwal, Anil eual. Water Sanitation Health of all?: Prospects for International Drinking Water Supply and Sanitation Decade. 1981-90. (London: Earthscan, 1985).

4. Briscoe, John and R. P. S Malik (eds), Handbook of Water Resources in India (New Delhi: Oxford University Press, 2007).

5. Briscoe, John and R. P. S Malik, the Water Economy of India: Bracing for Turbulence
(New Delhi: Oxford University Press and Washington D. C. : The World Bank, 2006).

6. Baghi, K., Ganges Delta. Calcutta University. 1944.

7. Chakraborty, S. C., Physiographic Evolution of Bengal Basin. In West Bengal. (Ed. A. B. Chatterjee, A. Gupta \& P. K. Mukhopadhayay. Calcutta 1969

8. Environment Protection Agency. http://www.epa.gov/ebtpages/alphabet.html.

9. Enviroment Protection Agency. Clean Water Act.

http://www.epa.gov/rowater/ewa.htm.

10. Environment Protection Agancy. List of Drinking Water Contaminants. http://www.epa.gov/salrwater/mcl/html.mcls

11. Environment Protection Agency. Safe Drinking Water Act.

http://www.epa.gov/safewater/sdwa.html

12. Environment Protection Agency. 2000 National Water Quality Inventory. http://www.epa.gov/305b/2000report

13. Ewan Mc Leish; Protecting Our PlanetKeeping Water Clean; Amazon Publisher: Vol (I):Oct.1990.

14. Miles Linthnoff; Water Conservation; Amazon Publisher; Vol (I); October 1995.

15. Mazumdar, S. C., Rivers of Bengal Delta, Caloutta University.1937.

16. Natural Resources Defence council. "What's on Tap: Grading Water in Cities." http://www.nrdc.org/water/dronking/cities/content s.asp. 